\title{
The Impact of the External Environment on the Growth of the Italian Academic Spin-Offs: A Cross-Sectional Analysis
}

\author{
Ivano De Turi ${ }^{1} \&$ Antonello Garzoni ${ }^{1}$ \\ ${ }^{1}$ Department of Economics and Management, University LUM Jean Monnet, Italy \\ Correspondence: Ivano De Turi, Department of Economics and Management, University LUM Jean Monnet, \\ Casamassima (BA), Italy. E-mail: deturi@lum.it
}

Received: March 28, 2018

doi:10.5539/ijbm.v13n8p16
Accepted: May 23, 2018

Online Published: June 30, 2018

URL: https://doi.org/10.5539/ijbm.v13n8p16

\begin{abstract}
In the last decade, there has been growing attention of the institutions towards the third mission of Universities. The university, along with their two fundamental goals of education and research, pursues a 'third mission', which means that it works to encourage the direct application, enhancement and use of learning to contribute to society's social, cultural and economic development. An instrument to pursue this mission is the creation by universities of academic spin-offs (ASOs) transferring the research results to the business world. This paper tested how the external environment would affect or not the performances of ASOs and in what terms. The dependent variable that best expresses growth, according to the academia, is the sales and the elements of the external environment. It wanted to test if the presence or not, in the province where the ASOs is located, of technology parks, business accelerators and incubators are influential. In this paper, it conducted a cross sectional analysis using an OLS examining the financial statements (31/12/2014) of 552 Italian ASOs.
\end{abstract}

Keywords: third mission, academic spin-offs, financial performance, external environment, entrepreneurship

\section{Introduction}

As well as education and research, the University pursues a third fundamental objective (so called third mission), the work that is to promote the direct application, enhancement and use of knowledge to contribute to the social, cultural and economic of the society. In this perspective, any structure within the University is committed to communicate and disseminate the knowledge through a direct relationship with the land and with all its stakeholders. Third Mission activity is a vitally important component of any university's role, whether it pictured as a third mission or as integral to the core missions of education/teaching/learning and research/scholarship. It is as important for the university in countless ways as it is for society. It is not new, but narrower notions of research excellence have overshadowed it, and academics have usually drawn themselves into something of a caste apart. However, Third Mission over the last decade revived. (Green Paper, European Commission, 2008). In Italy, the Legislative Decree n. 19/2012 set out the criteria of the Self-Assessment System, Periodic Evaluation and Accreditation, and then the Ministerial Decree n. 47/2013 has identified indicators and periodic evaluation parameters of research and third mission. They recognized in effect the third mission as an institutional mission of universities, alongside the traditional teaching and research missions (Anvur). Scientific and technological inventions produced by universities and moved to the market by new firms represent an option increasingly used for wealth creation that departs from the transfer of knowledge generated from research (Carayannis et al., 1998; Siegel et al., 2003; Vohora et al., 2004; Clarysse et al., 2005; Lockett et al., 2005). Moreover, the transfer of university-industry knowledge has become one of the main factors underpinning European innovation policies (Mueller, 2006). Different countries have thus created support units aimed specifically at strengthening the links between university and industry, with a strong focus on boosting and facilitating the creation of university-based companies (Criaco et al., 2013). The entrepreneurs, during their activities as students, professors or researchers at a university, acquire technological knowledge or develop a new technology that will, in the future, be used with the support of the university's business incubator (or another mechanism) to develop a product or a business concept that will be explored commercially by a new venture (Borges \& Filion, 2013). Academic spin-offs can be defined in two different sense. In a restrictive sense, as firms established on the basis of intellectual property generated within universities, in which the public body of research is directly present with share capital. In a general sense, where academic spin-offs firms are set up on 
the basis of competence and results obtained in the course of research programs, but which are not necessarily the subject of intellectual property rights transferred by the public to search the nascent enterprise. (Lazzeroni \& Piccaluga, 2003). According to our focus of research, we define academic spin-offs in a restrictive sense, as in which Universities and research centers are shareholders or founders.

\section{Comprehensive Model and Review of the Theoretical Context}

In this chapter, we represent the paper analysis model and a review of the theoretical context of every variables mentioned. The theoretical framework, that underline relationship among logical and linear variables, could be formulated as below.

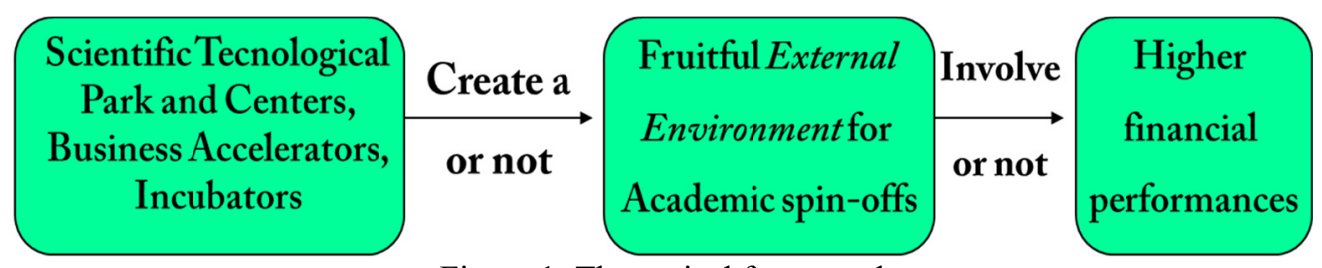

Figure 1. Theoretical framework

\subsection{Review of the Theoretical Context - The External Environment}

The external environment covers an important role, in entrepreneurship theory and research. The concept of external environment is intended to include those forces and elements external to the organization's boundaries that affect and are affected by an organization's actions as well as more general economic, sociocultural, political-legal, and technological forces which provide the broader context for the organization's operations (Covin, Slevin 1991). Several scholars have developed theories and conducted research that demonstrates the inseparability of the external environment from the entrepreneurial process. In this sense it's possible to understand how the different environmental conditions can encourage or hinder entrepreneurial activity (Bruno, Tyebjee 1982) and as they affect the impact of fiscal and regulatory environments (Kent, 1984), noting that political-legal forces can have a great impact on the pervasiveness and success of new ventures (Covin \& Slevin, 1991). Finally, after the examination of the several publications in field of external factors that influence academic spin-offs growth has emerged that the most influencer external factor is the regional and local context, followed by the University level, Networks, Technology transfer office and Incubatory. Regional and local context could play a key role in a programmatic phase and with an incentives plan. Therefore, the activities carried out by business incubators, business accelerator and technological park. Business Incubators and Business Accelerators operating both in pre-seed phase with training and consulting for the development of business idea. The incubators, however, after that also provide incubation services, which usually consist of space, utilities, administrative and logistic services. Technological Park, instead, aim to achieve a strong link between basic science, industrial research, technological development and innovation through collaboration with different actors (universities, firms..) and their activities consist of managing technological, logistic, real services, having laboratories and R\&D Centers, high tech companies and advanced services.

\subsection{Review of the Theoretical Context - Academic Spin-Offs}

The international growing rate of new venture science based in the last years demonstrate that this rate is higher when they are placed in a positive environmental context. In an era of knowledge-based competition, technology transfer from university to firms is a key issue for the wealth of nations and regions. In Italy, the first set of rules about academic spin-off took place in 1999, with Legislative Decree n. 297. This decree was an attempt to create the basis for promoting the activities of scientific and technological research by giving universities the possibility of interventions aimed at the creation of spin-offs. In order to diffuse an entrepreneurial culture of research, encourage the dissemination of scientific outcomes and support scientists through the stages of commercialisation of the results of their study, several universities have established technology transfer offices (TTOs). Spin-offs act as a significant medium in the technology transfer process between public and private sectors (Algieri et al., 2013).

\subsection{Review of the theoretical Context - Growth Indicators}

After a close examination of several publications in field of academic spin-offs growth indicators (Davidsson et al., 2005, Zhang, 2008, Zhou et al., 2010, Salvador, 2010, Wennberg et al., 2011, Criaco et al., 2014, Agostini et al., 2014, Novotny, 2014, Galati et al., 2016) has emerged that the most widely used growth indicator are the 
Sales. All of the authors cited, less then Zhang 2008, have identified as the most suitable indicator to calculate the growth, of the ASOs, the Sales. Considering the results of this literature review, for this work Sales will be used as growth indicator.

\section{Italian Academic Spin-Offs Scenario}

In this chapter we will present a qualitative analysis of the context of Italian academic spin-offs in order to highlight later the role of the external environment in their development. An analysis of a 1.219 spin-off sample from the spinoffricerca.it site showed that 220 operate in the ICT sector, 132 operate within the Environment, 134 others, 89 electronics, 89 services, 77 life sciences, 71 Biomedical, 69 energy, 47 automation, 46 medicine, 35 biotech, 33 chemistry, 32 biology, 27 sciences, 25 building, 24 communications, 23 pharmacy, 18 mechanics, 14 agri-food and 14 architecture. A summary is shown in the chart below.

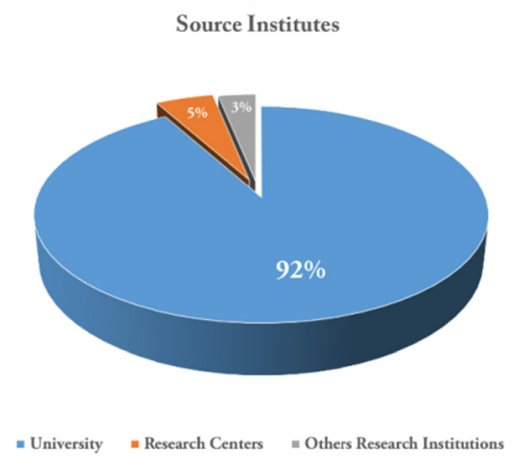

Figure 2. Italian academic spin-offs industries (Data source: spinoffricerca.it, own elaboration)

The $92 \%$ of italian academic spin-offs were founded by Universities, the rest by research centers $(5 \%)$ and by other research institutes $(3 \%)$ as shown the next graph.

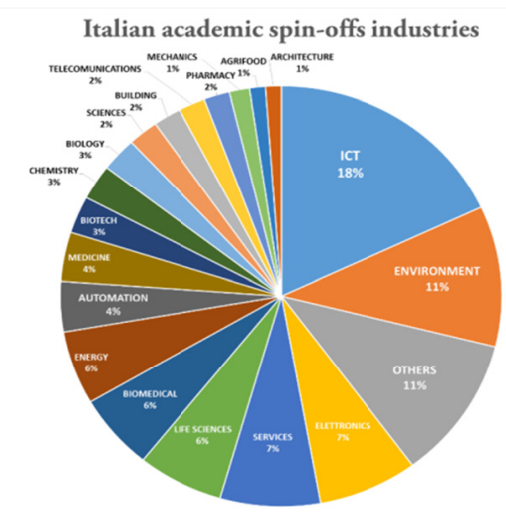

Figure 3. Source institutes

Data source: spinoffricerca.it, own elaboration.

There are 1.196 active spin-offs in Italy operating in different industries. The database used as a source of information on Italian academic spin-offs, is as already mentioned, the site spinoffricerca.it. It contains a census of all the information about the companies accredited as spin-offs by the source research organizations. The site, however, contains only general information about spin offs (name, VAT number, core activity, city, foundation details, ecc.). In order to get more information we have extended the search by VAT number on the site aida.bvdinfo.com with detailed information on 715 companies that represent the sample analyzed.

\section{Analysis of the Italian Academic Spin-Offs Sample}

Of these 715: 653 are active, 23 have closed (7 definitely, 3 for merger and 13 are in liquidation), 7 failed and 32 are in liquidation. Of these 715, 6 were constituted before 1990, 34 were created between 1990 and 2000,360 
between 2000 and 2010 and 315 from 2010 to present.

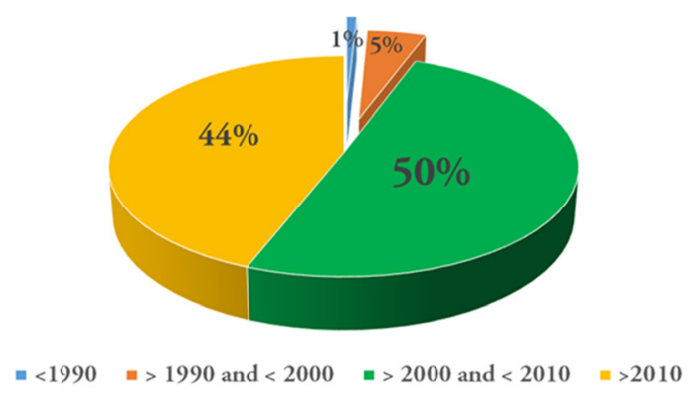

Figure 4. Italian academic spin-offs sample

Data source: spinoffricerca.it, own elaboration.

As shown the following map, of the 715 spin-offs analyzed are thus distributed across Italian territory. There are 84 in Tuscany, 80 in Lombardy, 77 in Emilia Romagna, 76 in Piedmont, 53 in Veneto, 49 in Lazio (the higher number of the central Italy regions), 46 in Apulia (the higher number of the south Italy regions), 39 in Liguria, 37 in Friuli Venezia Giulia, 35 in the Marche, 24 in Trentino-Alto Adige, 19 in Campania, Sardinia and Umbria, 18 in Calabria, 14 in Sicily, 12 in Abruzzo, 7 in Molise, 6 in Basilicata and 1 in Aosta Valley.

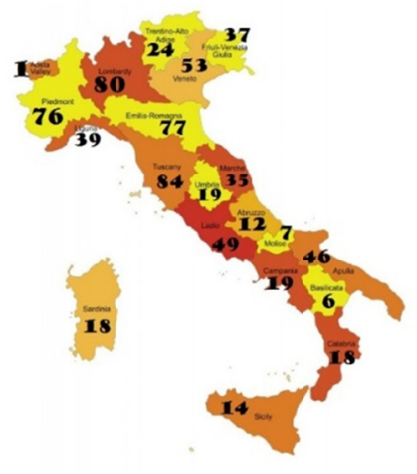

Figure 5. Geolocation of the 715 spin-offs analyzed on Italian (Data source: spinoffricerca.it, own elaboration)

From the point of view of the analysis of growth indicator (Sales), the largest part of ASOs in the sample has sales up to $50 \mathrm{k}(39 \%)$ and between $100 \mathrm{k}$ and $500 \mathrm{k}(32 \%)$, while only few get bigger. The next table shows what's just said in a summary graph.

Table 1. Italian academic spin-offs sample divided per revenues (2015) level

\begin{tabular}{l|c|}
\multicolumn{1}{|c|}{ Sales } & n. of ASO \\
\hline$<50 k$ & 280 \\
\hline$>50 k$ and $<100 k$ & 98 \\
\hline$>100 k$ and $<500 k$ & 231 \\
\hline$>500 k$ and $<1 \mathrm{~m}$ & 51 \\
\hline$>1 \mathrm{~m}$ and $<5 \mathrm{~m}$ & 46 \\
\hline$>5 \mathrm{~m}$ & 8 \\
\hline
\end{tabular}




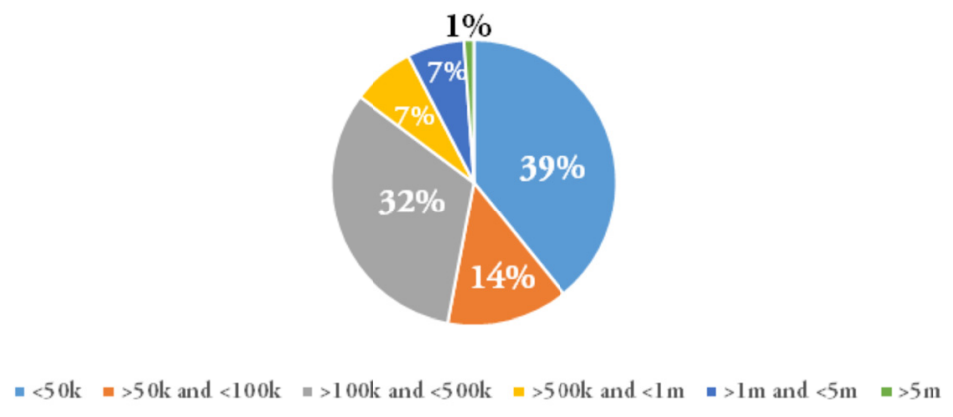

Figure 6. Italian academic spin-offs sample divided per revenues (2015) level

Data source: spinoffricerca.it, own elaboration.

After this brief explanation of the Italian ASOs scenario, in the next chapter it will describe the methodology of the model and their results.

\section{Methodology}

The chosen methodology, to perform the empirical survey in this work, is the Ordinary Least Square (OLS) regression. OLS is a statistical technique that attempts to find the function, which most cllosely approximates the data in order to explain if, and to what extent, exist a relationship between dependent and independent variable used. In technical terms, the OLS method used to fit a straight line through a set of data-points, so that the sum of the squared vertical distances (called residuals) from the actual data-points is minimised (Note 1). Linear regression allows us to estimate the coefficients, make inferences and estimate the causal effect on $\mathrm{Y}$ of a unit change in $\mathrm{X}$ variables, holding all the other variables constant; it is possible to use a regression with a single regressor or a multiple regression model, depending on the kind of survey (Stock \& Watsion, 2005). In this work, we use a multiple regression model. The general equation for the linear multiple regression model is the following:

$$
Y=\beta_{0}+\beta_{1} X_{1 i}+\beta_{2} X_{2 i} \ldots+\beta_{K} X_{k i}+\varepsilon_{i}
$$

Where:

- $\quad \mathbf{Y}$ is the dependent variable;

- $\mathbf{X} \mathbf{1}, \mathbf{X} \mathbf{2}$ and $\mathbf{X}_{\mathbf{k}}$ are the independent variables (regressors);

- $\quad \boldsymbol{\beta 0}$ is the intercept (constant);

- $\quad \boldsymbol{\beta} 1$ is the effect on $\mathrm{Y}$ of a change in $\mathrm{X}_{1}$, holding all the other variables constant;

- $\quad \boldsymbol{\beta 2}$ is the effect on $\mathrm{Y}$ of a change in $\mathrm{X}_{2}$, holding all the other variables constant and so on for the other coefficients;

- $\varepsilon_{\mathrm{i}}$ is the regression error due to the factors that influence $\mathrm{Y}$ but are not included in the regression function (omitted variables).

In this work, the equation used to explain the relationship between financial performance and external environment roles is the following:

$$
\text { LnSALES }=\beta_{0}+\beta_{1} L n A G E+\beta_{2} L n A S+\beta_{3} E M+\beta_{4} L F+\beta_{5} S T P C+\beta_{6} B A+\beta_{7} I N+\varepsilon_{i}
$$

Where:

- LnSALES is the natural logarithm of sales (2014) of the sample (552 italian's ASO's);

- $\quad \boldsymbol{\beta}_{0}$ is the constant, $\boldsymbol{\beta}$ (from 1 to 7 ) are the variable coefficients and $\boldsymbol{\varepsilon}_{i}$ is the regression error;

- LnAGE is the natural logarithm of the total number of days between the date of creation of the ASO's and December 31th, 2014; (Note 2)

- $\quad$ LnAS is the natural logarithm of the total asset (2014); it refers to the total amount of assets owned by a firm; ${ }^{2}$ 
- $\quad$ EM is the EBITDA (Note 1) margin, obtained dividing EBITDA by total sales; this result helps show how much operating expenses are eating into a company's profits.

- $\quad \mathbf{L F}$ is a dummy variable that represents the legal form of the ASO (1 if is S.r.l. and 0 if is S.p.a.);

- $\quad$ STPC is a dummy variable that represents the presence (1) or not (0), in the province of the legal address of the ASO, of a Scientific/Technological Park or Center (Note 2);

- $\quad$ BA is a dummy variable that represents the presence (1) or not (0), in the province of the legal address of the ASO, of a Business Accelerator ${ }^{4}$;

- IN is a dummy variable that represents the presence (1) or not (0), in the province of the legal address of the ASO, of an Incubator ${ }^{4}$;

It uses the natural logarithm of total sales (LnSALES) as dependent variable as Wennberg et al. (2011) that estimated a model for growth in terms of sales using the formula $\log \left(\mathrm{size}_{1} / \mathrm{size}_{0}\right)$ to compute the growth rate. In this paper, using a cross-sectional analysis it estimated a model for growth using the formula $\log \left(\operatorname{size}_{2014}\right)$ to obtain as result the effect, in percentage, on $\mathrm{Y}$ of a change in independent variable, holding all the other variables constant. The percentage change in $\mathrm{Y}$ is equal to $(100 * \Delta \mathrm{Y} / \mathrm{Y})$; a change in $\mathrm{X}$ by one unit $(\Delta \mathrm{X}=1)$ is associated with a $100 * \beta 1 \%$ change in $Y$ (Stock \& Watson, 2005). The logarithm also has the advantage to transform the sales value in a smaller number easier to use. This is the case of a "log-linear" function (Note 3 ) because just the dependent variable (and none of independent variables) is a natural logarithm.

The control variables used, pursuant to the most relevant literature (Rodriguez et al., 2016), in this survey are the following:

1. Ln of Age (LnAge)

2. Ln of Total assets (LnAS);

3. EBITDA margin (EM);

4. Legal form (LF).

The external environment variables (STPC, BA and IN) are the three variables that It analyses with the aim to understand if, and to what extent, there is a relationship (positive or negative but especially statistically significant) able to influence the ASO's Sales.

\section{Analysis}

The main findings of the investigation about the relationship between external environment and ASO's Sales presented in this section. The descriptive statistics represented in Table 2.

Table 2. Descriptive statistic (source: personal estimation)

\begin{tabular}{llcccc}
\hline VARIABLES & MEAN & MEDIAN & MIN. & MAX. & ST. DEV. \\
\hline LNSA & 4,86 & 4,80 & 2,28 & 10,8 & 1,41 \\
LNAGE & 7,67 & 7,74 & 4,73 & 9,81 & 0,736 \\
LNAS & 5,3 & 5,2 & 2,02 & 12,0 & 1,42 \\
EM & 0,0859 & 0,13 & $-20,2$ & 12,7 & 1,27 \\
LF & 0,973 & 1,00 & 0,00 & 1,00 & 0,163 \\
SCPC & 0,542 & 1,00 & 0,00 & 1,00 & 0,499 \\
BA & 0,562 & 1,00 & 0,00 & 1,00 & 0,497 \\
IN & 0,534 & 1,00 & 0,00 & 1,00 & 0,499 \\
\hline
\end{tabular}

It is important to point out, as shown in Table 1, that the average value of the ASO's Sales is 4,86 (with a median of 4,80). This result is consistent with the one obtained by Lipton \& Lorsch (1992). Table 2 illustrates the correlations among different explanatory control and dependent variables used in the regression analysis. 
Table 3. Matrix correlation

\begin{tabular}{lcccccccc}
\hline & LNSA & LNAGE & LNAS & LF & EM & SCPC & BA & IN \\
\hline LNSA & $\mathbf{1 , 0 0}$ & & & & & & & \\
LNAGE & 0,4591 & $\mathbf{1 , 0 0}$ & & & & & \\
$p$-value & 0,0000 & & & & & & \\
LNAS & 0,7940 & 0,5158 & $\mathbf{1 , 0 0}$ & & & & \\
$p$-value & 0,0000 & 0,0000 & & & & & \\
LF & $-0,2943$ & $-0,1315$ & $-0,3656$ & $\mathbf{1 , 0 0}$ & & & \\
$p$-value & 0,0000 & 0,0020 & 0,0000 & & & & \\
EM & $-0,0520$ & $-0,0361$ & $-0,1306$ & 0,2319 & $\mathbf{1 , 0 0}$ & & \\
$p$-value & 0,2226 & 0,3972 & 0,0021 & 0,0000 & & & \\
SCPC & $-0,0246$ & $-0,0370$ & 0,0141 & 0,0699 & 0,0539 & $\mathbf{1 , 0 0}$ & \\
$p$-value & 0,5641 & 0,3854 & 0,7416 & 0,1010 & 0,2062 & & & \\
BA & 0,1023 & 0,1135 & 0,1408 & $-0,0578$ & $-0,0146$ & 0,1618 & $\mathbf{1 , 0 0}$ & \\
$p$-value & 0,0162 & 0,0076 & 0,0009 & 0,1747 & 0,7321 & 0,0001 & & \\
IN & 0,1243 & $-0,0148$ & 0,0922 & $-0,0666$ & $-0,0136$ & $-0,1151$ & 0,0902 & $\mathbf{1 , 0 0}$ \\
$p$-value & 0,0034 & 0,7294 & 0,0303 & 0,1178 & 0,7505 & 0,0068 & 0,0340 & \\
\hline
\end{tabular}

Source: personal estimation.

Outliers do not affect the dataset because, as it is possible to note in Table 1, mean and median are very similar values. As shown in Table 2, an interesting finding from the correlation matrix is that the presence in the province of the legal address of the ASO of an Incubator is positively related to the natural logarithm of Sales $(0,12)$. Contemplating probably the fact that most of the firms with localized "near" an Incubator could be able to achieve better financial performance than others could. The higher correlation coefficient regards the relationship between the natural logarithm of sales (dependent variable) and the natural logarithm of total assets $(0,79)$, demonstrating that the firm size in a determinant factor to improve the financial performance. There are not too high correlation coefficients and this could indicate that collinearity does not affect the sample. The OLS regression results obtained presented in Table 3. The results are robust to the effect of multicollinearity, outliers and non-linearity. It runs a "White Test" to understand if there is a heteroskedasticity problem, (the error terms, do not have constant variance) and the results are that heteroskedasticity does not affect the sample.

Table 4. Pooled OLS regression (Dependent variable: Ln Sales 2014 (LnSA))

\begin{tabular}{lllll}
\hline VARAIBLE & COEFFICIENT & ST. DEV. & T & P-VALUE \\
\hline CONST & $-0,04$ & 0,47 & $-0,08$ & 0,935 \\
LNAGE & $0,13^{* *}$ & 0,06 & 2,31 & 0,0210 \\
LNAS & $0,75^{* * *}$ & 0,03 & 23,32 & $<0,0001$ \\
LF & $-0,15$ & 0,25 & $-0,60$ & 0,5519 \\
EM & $0,06^{* *}$ & 0,03 & 2,08 & 0,0379 \\
SCPC & $-0,07$ & 0,07 & $-0,99$ & 0,3225 \\
BA & $-0,04$ & 0,08 & $-0,49$ & 0,6274 \\
IN & $0,15^{* *}$ & 0,07 & 2,04 & 0,0423 \\
R ADJUSTED & 0,636 & & & \\
No. obs. & 552 & & & \\
\hline
\end{tabular}

$* * *$ significance at $1 \%$ level, $* *$ significance at $5 \%$ level, $*$ significance at $10 \%$ level

Source: personal estimation.

As is possible to note in Table 3 the control variables (LnAge, LnAS and EM) are statistically significant at 1\% or $5 \%$ level but in this work we comment and discuss just significant external environment variables (IN). The findings, with regard to the link between the presence in the province of the legal address of the ASO of an Incubator and Sales seem to demonstrate that a positive relationship exists and that this link is statistically significant. Better financial performance, in terms of Sales, characterized firms localized "near" an Incubator. The adjusted R2 value is high $(0,636)$ and it means that more than $60 \%$ of the variance in the LnSA explained by the independent variables used in this model. 
The highest variance inflation factor (VIF) in the regression model is considerably within the limit as none of VIF approached the critical value of 10 , as shown in Table 4. The highest coefficient regards the natural logarithm of total assets and is equal to 1.59 . This is the reason why it is possible to assert that multicollinearity (when one of the regressors is an exact linear function of the other regressors) does not affect this dataset.

Table 5. Multicollinearity test and VIF

\begin{tabular}{lclc}
\hline VARIABLE & VIF COEFFICINET & VARIABLE & VIF COEFFICIENT \\
\hline LNSA & Dependent variable & EM & 1,06 \\
LNAGE & 1,39 & SCPC & 1,06 \\
LNAS & 1,59 & BA & 1,06 \\
LF & 1,22 & IN & 1,04 \\
\hline
\end{tabular}

Source: personal estimation.

According the aforementioned regression results it is possible write the equation as following, substituting the coefficients of regression in the formula:

$$
\begin{aligned}
\text { LnSALES }=-0,04 & +0,13 \text { LnAge2014 }+0,75 \text { LnAssets } 2014-0,015 \text { LegalForm } \\
& +0,06 \text { EBITDAmargin2014 - 0,07Scientific Technological Park Center } \\
& -0,04 \text { Business Accelerator }+0,15 \text { Incubator }
\end{aligned}
$$

\section{Conclusions and Limitations}

In conclusion, we can say that the external environment influences the growth of ASOs and especially the presence of incubators is a fruitful context for growth. The presence in the province of the legal address of the ASO of an Incubator involve higher Sales. This statement also supported by what expressed by some of the academic spin-off members interviewed in the course of the present research. They confirmed that proximity to the university or business incubators would allow them to participate in organizing events and take advantage of destructured resource (stage, student internship, ...) that somewhat enrich the spin-offs.

As far as the limits of this research, focusing exclusively on single year data, it is not possible to test the effect of the years on the results themselves and therefore, for future studies, we may want to consider using panel data. Furthermore, in order to clean up the results from reverse causality. We could evaluate the possibility of using a dynamic panel (GMM) or search an instrumental variable with which to integrate the model.

\section{References}

Agostini, L., Filippini, R., \& Nosella, A. (2016). Protecting intellectual property to enhance firm performance: does it work for SMEs\&quest. Knowledge Management Research \& Practice, 14(1), 96-105. https://doi.org/10.1057/kmrp.2014.20

Algieri, B., Aquino, A., \& Succurro, M. (2013). Technology transfer offices and academic spin-off creation: the case of Italy. Journal of Technology Transfer, 38, 382. https://doi.org/10.1007/s10961-011-9241-8_

Borges, C., \& Filion, L. J. (2013). Spin-off Process and the Development of Academic Entrepreneur's Social Capital. J.Technol. Manag. Innov, 8(1). http://dx.doi.org/10.4067/S0718-27242013000100003

Bruno, A., \& Tyebjee, T. (1982). Developing the Marketing Concept in Public Accounting. Journal of the Academy of Marketing Science, 10, 165. https://doi.org/10.1007/BF02721906

Carayannis, E., Rogers, E., Kuriharac, K., \& Allbritton, M. (1998). High-technology spinoffs from government R\&D laboratories and research universities. Technovation, 1-11. https://doi.org/10.1016/S0166-4972(97)00101-6

Clarysse, B., Wright, M., Lockett, A., Van de Velde, E., \& Vohora, A. (2005). Spinning out new ventures: A typology of incubation strategies from European research institutions. Journal of Business Venturing, 183-216. https://doi.org/10.1016/j.jbusvent.2003.12.004

Covin, J. G., \& Slevin, D. P. (1991). A Conceptual Model of Entrepreneurship as Firm Behavior. Entrepreneurship Theory and Practice, 16(1), 7-25. https://ssrn.com/abstract=1504448

Criaco, G., Minola, T., Serarols, C., \& Bhatiya, A. (2013). Companies Spun Out of Universities: Different Typologies for Different Performance Patterns. Handbook of Research on Techno-Entrepreneurship, 2. 
https://ssrn.com/abstract $=2346976$

Davidsson, P., Achtenhagen, L., \& Naldi, L. (2005). Research on small firm growth: A review. Paper presented at the 35th EISB Conference. Barcelona, Spain. Retrieved from http://citeseerx.ist.psu.edu/viewdoc/download?doi=10.1.1.573.4282\&rep=rep1\&type=pdf

De Turi, I., \& Garzoni, A. (2014). The role of academic spin offs in entrepreneurial innovation and regional development: the Apulia case. European Journal of Economics and Management, 2(2). Retrieved from http://www.ejemjournal.com/EJEM_2015_Vol.2_No.2-SPECIAL_ISSUE.pdf

Festel, G. (2015) Technology transfer models based on academic spin-offs within the industrial biotechnology sector. International Journal of Innovation Management, 19(4), 134-137. https://doi.org/10.1142/S1363919615500310

Florentina, C. (2013). Regional Development And Innovation In Romania. Challenges And Perspectives. Annals of Faculty of Economics, 234-242. http://anale.steconomiceuoradea.ro/volume/2013/n1/025.pdf

Galati, F., Bigliardi, B., Petroni, A., \& Marolla, G. (2016). Which factors are perceived as obstacles for the growth of Italian academic spin-offs?. Technology Analysis \& Strategic Management, 29(1), 84-104. https://doi.org/10.1080/09537325.2016.1199853

Green Paper, $\quad$ European Commission. $\quad$ (2008). Retrieved from http://ec.europa.eu/internal_market/copyright/docs/copyright-infso/greenpaper_en.pdf

Kent, C. (1984). The Environment for Entrepreneurship. Sloan Management Review .

Lazzeroni, M., \& Piccaluga, A. (2003). Towards the Entrepreneurial University. Local Economy. https://doi.org/10.1080/0269094032000073807

Lipton, M., \& Lorsch, J.W. (1992). A modest proposal for improved corporate governance. Business Lawyer, 48(1), 59-77. https://doi.org/10.12691/jfa-2-4-2

Lockett, A., Siegel, D., Wright, M., \& Ensley, M. D. (2005). The creation of spin-off firms at public research institutions: Managerial and policy implications. Research Policy, 981-93. https://doi.org/10.1016/j.respol.2005.05.010

Markman, G., Phan, H., Balkin, D., \& Gianiodis, P. (2005). Entrepreneurship and university-based technology transfer . Journal Of Business Venturing, 20(2), 241-263. https://doi.org/10.1016/j.jbusvent.2003.12.003

Mueller, P. (2006). Exploring the knowledge filter: How entrepreneurship and university-industry relationships drive economic growth. Research Policy, 1499-508. Retrieved from www.econ.mpg.de/files/2006/.../Mueller_knowledgestartups.pdf

Netval. (2008). Annual Report. Retrieved from https://netval.it/static/media/uploads/files/20090507_Rapporto_Netval_2008.pdf

Novotny, A. (2014). Motivation and Success of Academic Spin-Offs; Evidence from Hungary, The Annals of the University of Oradea, 23, 1212-1219. Retrieved from http://steconomiceuoradea.ro/anale/volume/2014/n1/135.pdf

Parente, R., \& Feola, R. (2013). Entrepreneurial intent and entrepreneurial commitment of young researchers. International Journal of Technology Management \& Sustainable Development, $12(2)$. http://dx.doi.org/10.1386/tmsd.12.2.155 1

Quetglas, G. M., \& Grau, B. G. (2002). Aspects of University Research and Technology Transfer to Private Industry. Journal of Business Ethics, 39(1), 51-58. https://doi.org/10.1023/A:1016375832641

Rodríguez-Gulías, M., Fernández-López, S., \& Rodeiro-Pazos, D. (2016). Growth determinants in entrepreneurship: A longitudinal study of Spanish technology-based university spin-offs. Journal of International Entrepreneurship, 14(3), 323-344. https://doi.org/10.1007/s10843-016-0185-9

Salvador, E. (2010). How effective are research spin-off firms in Italy? Rev Écon Ind, 99-122. https://doi.org/10.4000/rei.4972

Siegel, D. S., Waldman, D., \& Link, A. (2003). Assessing the impact of organizational practices on the relative productivity of university technology transfer offices: An exploratory study. Research Policy, 27-48. https://doi.org/10.1016/S0048-7333(01)00196-2

Stock, J. H., \& Watson, M. W. (2005). Implications of Dynamic Factor Models for VAR Analysis. Harvard 
University. https://doi.org/10.3386/w11467

Vohora, A., Wright, M., \& Lockett, A. (2004). Critical junctures in the growth in university high-tech spinout companies. Research Policy, 147-75. https://doi.org/10.1299/jsmeicbtt.2002.1.0_12

Wennberg, K., Wiklund, J., \& Wright, M. (2011). The effectiveness of university knowledge spillovers: Performance differences between university spinoffs and corporate spinoffs. Research Policy, 40(8), 1128-1143. https://doi.org/10.1016/j.respol.2011.05.014

Zhang, J. (2009). The performance of university spin-offs: an exploratory analysis using venture capital data. The Journal of Technology Transfer, 34(3), 255-285. https://doi.org/10.1007/s10961-008-9088-9

Zhou, Y., T. Minshall, et al. (2010). Building Innovation Capabilities: An Inquiry into the Dynamic Growth Process of University Spin-outs in China. Int. J. Innovation and Technology Management, 7(3), 273-302. https://doi.org/10.1142/S0219877010002082

\section{Notes}

Note 1. Source: http://www.strath.ac.uk

Note 2. Regarding firm-specific characteristics, firm size was measured as the natural logarithm of the firm assets (LN_ASSETS). Similarly, I also used the natural logarithm of the age of the firm (LN_AGE).

Note 3. EBITDA: Earnings Before Interest, Taxes, Depreciation and Amortization is an important standard measure of profitability allows analysts to generate useful comparisons between companies, and to project long-term profitability.

Note 4. Fonte: http://www.economyup.it

Note 5. The "log-linear" function: $\ln (\mathrm{Yi})=\mathrm{b} 0+\mathrm{b} 1 \mathrm{Xi}+\varepsilon \mathrm{i}$

\section{Copyrights}

Copyright for this article is retained by the author(s), with first publication rights granted to the journal.

This is an open-access article distributed under the terms and conditions of the Creative Commons Attribution license (http://creativecommons.org/licenses/by/4.0/). 